Check for updates

Cite this: RSC Adv., 2019, 9, 25184

\title{
Zein film functionalized with gold nanoparticles and the factors affecting its mechanical properties $\uparrow$
}

\author{
Mohammed Ajmal Puthiyaveetil Yoosaf, ${ }^{a}$ Anjana Jayaprakash, ${ }^{a}$ Somnath Ghosh, ${ }^{a}$

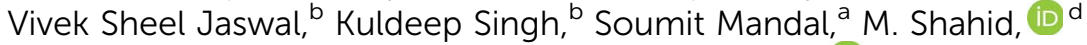 \\ Munendra Yadav, ${ }^{e}$ Subhojit Das ${ }^{\star c}$ and Pankaj Kumar (D)*a
}

In this article, we report a simple method to synthesize biodegradable zein films functionalized with gold nanoparticles (AuNPs) with significantly improved mechanical properties, as an environmentally benign substitute to biologically hazardous polymers. Zein-coated AuNPs were synthesized using the zein

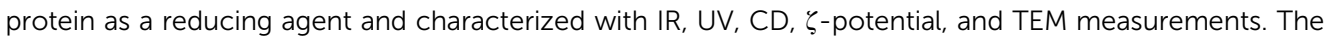
zein protein interaction with the negatively charged surface of AuNPs provides excellent strength to the zein thin film. For the first time, FT-IR spectral studies suggested the strong interaction between AuNPs and zein protein, which was further supported by the higher binding constant $\left(K_{b}\right)$ value. The films were characterized for mechanical properties with spectroscopic and physical experimental investigations. The surface morphology of AuNP-doped zein film was explored by AFM and SEM, which suggested that the AuNPs prevent the buckling of zein film and increase the strength as well as flexibility of the film.

Received 17th June 2019

Accepted 6th August 2019

DOI: $10.1039 / c 9 r a 04527 a$

rsc.li/rsc-advances barrier property, tensile strength, flexibility, and gas permeability need to be regulated in order to transform zein into an alternative to polythene. The inherent brittleness of zein restricts its application as a structural material. ${ }^{13}$ This can be improved by treating it with plasticizers, such as polyols, oligosaccharides, lipids, and fatty acids prior to casting in order to make zein films more useful. ${ }^{14,15}$ Addition of plasticizers increase the strength and flexibility of the zein films, however, excess will make them too weak and sticky to be handled. ${ }^{16}$

Several studies have been conducted with the aim to improve the functional properties of zein films using various physical and chemical modification techniques. ${ }^{17-19}$ Incorporation of nanoparticles (NPs) into the thin films of zein protein can be used as a strategy to impart the desired tensile strength and flexibility to the films by enhancing fibrillation..$^{20-22}$ Nevertheless, the mechanism for protein-NP interaction leading to improved mechanical properties is underexplored and still is a topic of great interest due to its wide range of applications. ${ }^{23,24}$

Here, we report the synthesis and characterization of zein protein film doped with gold-nanoparticles (AuNPs) having enhanced mechanical properties as an alternative to the synthetic polymer. In this regards, first, the AuNPs functionalized with zein protein were synthesized (vide infra) and characterized. ${ }^{25-27}$ Binding constant $\left(K_{\mathrm{b}}\right)$ and Fourier Transform Infrared (FT-IR) spectral measurement suggest a strong interaction between the AuNPs and zein protein. These interactions provide the ground to develop a method to prepare AuNP doped zein film where the reaction conditions were most optimum and economic (i.e., NTP). AFM, SEM and spectral characterization of zein films suggested that the strong binding of AuNPs 
with zein enhances the fibrillation and therefore declines the buckling or otherwise provides extraordinary strength to the film. Physical parameters such as tensile strength and strain also demonstrate explicitly that the AuNP doped zein film is an ideal substitute for the biologically hazardous polymer. The present study, for the first time, explains how the AuNP interaction with zein provides enhanced strength and strain to the zein film.

AuNPs, doping agent for the zein thin film, was prepared by heating an aqueous solution of $\mathrm{HAuCl}_{4}$ with zein protein in the presence of SDS (ESI, $\dagger$ ES). ${ }^{26}$ The solution color changed from yellowish to pink, indicating the conversion of tri-cationic gold $\left(\mathrm{Au}^{3+}\right)$ to the AuNPs. UV-visible spectral measurement of the above reaction showed the formation of a band at $550 \mathrm{~nm}$ (Fig. 1a). Surface Plasmon Resonance (SPR) absorption band at $550 \mathrm{~nm}$ is a characteristic feature for AuNPs. The reaction followed the first order rate kinetics, and the pseudo-first order rate constant determined to be $1.25 \times 10^{-3} \mathrm{~s}^{-1}$ (ESI, Fig. S1a † To determine the best suitable temperature for uniform AuNP formation with the highest yield, we followed the formation of NPs by UV-visible spectral measurements as a function of temperature $\left(20-90^{\circ} \mathrm{C}\right)$ and found it to be $65^{\circ} \mathrm{C}$ (Fig. 1b; ESI, ES, and Fig. S1 $\left.\mathrm{b}_{\dagger}\right)$. Also, we determined the optimal zein amount for AuNP synthesis by following the $550 \mathrm{~nm}$ peak in UV-visible spectral measurements and observed to be $0.15 \%$ with $0.20 \mathrm{mM} \mathrm{HAuCl}_{4}$ (ESI, ES, and Fig. S2 $\dagger$ ) (Scheme 1).

To gain insight into the zein coated AuNP formation and their interaction with zein protein, which provides strength to the zein film, circular dichroism (CD) and FT-IR spectroscopic measurements were carried out. The $\mathrm{CD}$ spectra of zein exhibited a band at $222 \mathrm{~nm}$ due to peptide $\mathrm{n}-\pi^{*}$ transition, (a)
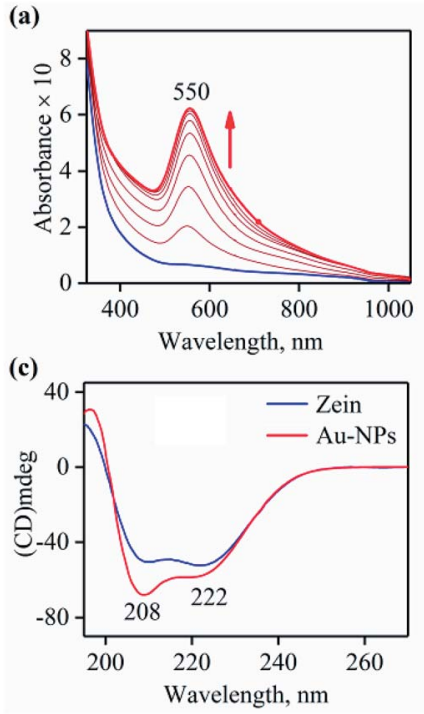

(b)

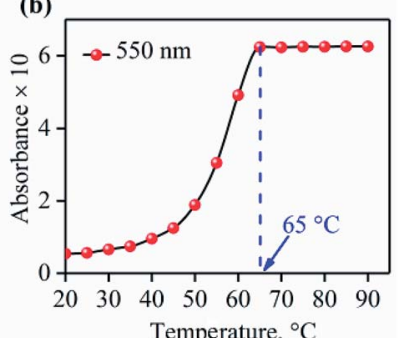

(d)

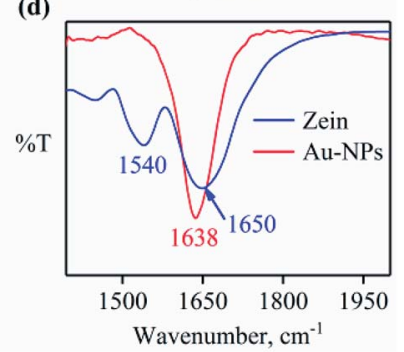

Fig. 1 (a) UV-visible spectral changes of zein protein $(0.20 \%$; black line) upon addition of $\mathrm{HAuCl}_{4}(0.20 \mathrm{mM}$, red line) in $10 \mathrm{mM}$ SDS aqueous solution at $65^{\circ} \mathrm{C}$. (b) UV-visible spectral titration monitored at $550 \mathrm{~nm}$ for the formation of AuNPs as a function of temperature (from $20^{\circ} \mathrm{C}$ to $90^{\circ} \mathrm{C}$ ). (c) CD spectra of zein (blue line) and AuNPs (red line) recorded in aqueous medium at $25^{\circ} \mathrm{C}$ (d) FT-IR spectra of zein (blue line) and AuNPs (red line) recorded in $\mathrm{KBr}$ at $25^{\circ} \mathrm{C}$.

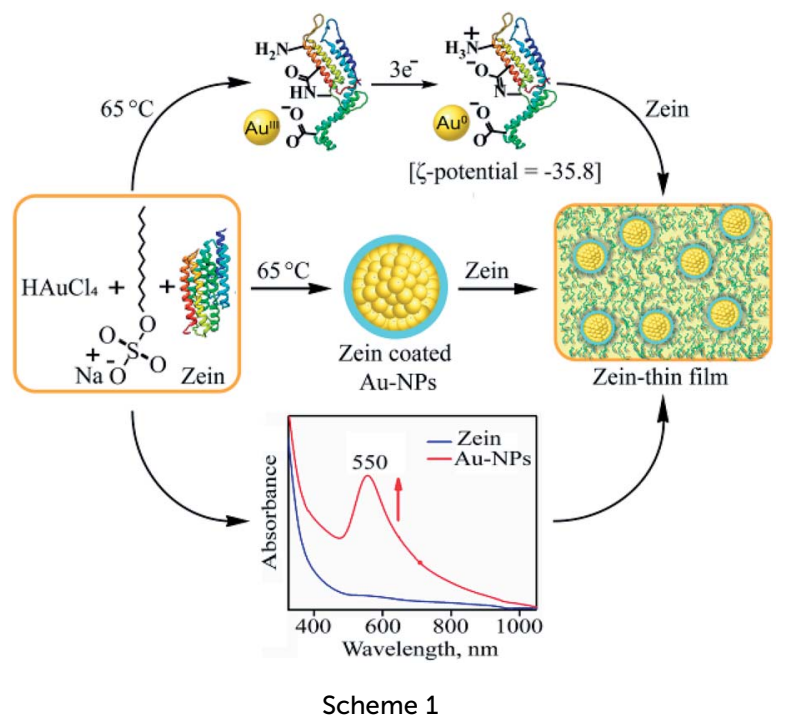

characteristic of typical alpha-helical structure and the band at $208 \mathrm{~nm}$ represents exciton splitting of lowest peptide $\pi-\pi^{*}$ transition (Fig. 1c) ${ }^{28-30}$ The change in CD spectra of zein (red) is attributed to the unfolding of zein or immobilization of zein on AuNPs, reflecting the surface functionalization of the AuNPs. The unfolding of zein in aqueous $\mathrm{HAuCl}_{4}$ solution in the presence of surfactant leads to an exposure of cysteine which initiate the reduction of $\mathrm{Au}^{3+}$ to $\mathrm{Au}^{0} .^{31-33}$ This result can be correlated to the change in the secondary structure of zein protein when functionalized on AuNPs. ${ }^{34}$ To elaborate further, the CD measurement of zein by varying the temperature from $20^{\circ} \mathrm{C}$ to $90{ }^{\circ} \mathrm{C}$ suggested that zein denatured in the range of $65{ }^{\circ} \mathrm{C}$ to $80^{\circ} \mathrm{C}$ (Fig. S3a $\dagger$ ). Interestingly, the CD spectrum of a mixture of zein plus AuNPs $\left(45^{\circ} \mathrm{C}\right)$, as otherwise in case of AuNP doped zein film, exactly matches with the CD spectrum of only zein at $80{ }^{\circ} \mathrm{C}$ (Fig. S3b $\dagger$ ). This result suggests that the presence of $\mathrm{Au}^{3+} /$ AuNPs enhances the zein unfolding/denaturation and hence explain the clear temperature-dependent transitions of AuNP formation as or else shown in the UV-visible titration curve (Fig. 1b). The FT-IR spectrum of zein exhibited a characteristic peak at $1650 \mathrm{~cm}^{-1},{ }^{35}$ corresponding to an amide $\mathrm{C}=\mathrm{O}$ stretching of peptide chain shifted to $1638 \mathrm{~cm}^{-1}$ in zein-AuNPs due to the interaction of amide functional groups with $\mathrm{Au}^{0}$ of AuNPs (Fig. 1d; ESI, Fig. S4 $\dagger$ ). ${ }^{36}$ Disappearance of the peak at $1540 \mathrm{~cm}^{-1}$ $(\mathrm{N}-\mathrm{H})$, suggests the removal of $\mathrm{H}^{+}$from $\mathrm{N}-\mathrm{H}$ and therefore create a negative charge on amide $\mathrm{N}$-atom. The distribution of charge on $-\mathrm{N}-\mathrm{C}=\mathrm{O}$ moiety is responsible for shifting/ decreasing of $\mathrm{C}=\mathrm{O}$ peak to $1636 \mathrm{~cm}^{-1}$. This was additionally supported from the $\zeta$-potential measurement, which suggested a negative charge on the surface of AuNPs (-35.8 mV) (ESI Fig. S5 $\dagger$ ), which was further confirmed by gel electrophoresis (ESI Fig. S6†). ${ }^{37}$ Furthermore, Transmission Electron Microscopy (TEM) images (Fig. S7a $\dagger$ ) of AuNPs prepared by zein $(0.15 \%$ w/v) with $\mathrm{HAuCl}_{4}(0.20 \mathrm{mM})$ showed that the particles were mostly spherical (Fig. S7a $\dagger$ ) with an size around $\sim 27 \pm 5 \mathrm{~nm}$. TEM images of AuNPs of the same sample show clearly that the zein adheres to the surface of AuNPs (Fig. S7b †). 
We then attempted to prepare and characterize the biodegradable AuNP functionalized zein-protein film. AuNP doped zein protein film was prepared by mixing the solution of zein $(0.75 \mathrm{~g}, 7.5 \% \mathrm{w} / \mathrm{v})$ in aqueous ethanol $(80 \% \mathrm{v} / \mathrm{v})$, glycerol $(0.25 \mathrm{~g}$, $2.5 \% \mathrm{w} / \mathrm{v}$ ) as plasticizer and a freshly prepared AuNP suspension $(15 \% \mathrm{v} / \mathrm{v}$, vide supra) (ESI, $\dagger \mathrm{ES})$. Different experiments were performed to evaluate various physical parameters of the AuNP doped zein film. In this regards, first, we calculated the binding constant $\left(K_{\mathrm{b}}\right)$ for AuNPs with zein protein to understand the strength of the interaction between the two components. We have calculated the $K_{\mathrm{b}}$ by the fluorescence spectroscopic measurements as zein protein is known to show fluorescence due to the presence of tyrosine (5.25\%, major component), rather tryptophan $\left(0.16 \%\right.$, minor component). ${ }^{38,39}$ The binding constant was found to be $9.22 \pm 1.195 \times 10^{10} \mathrm{M}^{-1}$, using SternVolmer equation, suggesting the reasonably good binding of AuNPs with zein protein (Fig. 2a; ESI, ES and Fig. S8, ESI $†$ ). ${ }^{40,41}$ The Hill coefficient $(n)$ determined to be $1.028( \pm 0.1391)$, which is due to the enhanced degree of cooperativity in binding of zein with AuNP surface, suggesting a strong interaction between the immobilized AuNPs' surface ligand and zein. ${ }^{42}$ Interaction of zein with AuNPs and change in the conformation of protein was confirmed using $\mathrm{CD}^{43}$ The spectra of zein protein with or without AuNPs are different from each other and showed two negative peaks at about $\sim 207-210 \mathrm{~nm}$ and $220 \mathrm{~nm}$ with a positive one around $192 \mathrm{~nm}$, suggesting a typical protein with $\alpha+$ $\beta$ structure, in which intensity of $\alpha$-helix is more than $\beta$-sheet structure (Fig. $2 \mathrm{~b}$; ESI, ES, ESI $\dagger$ ). ${ }^{44-46}$ This indicates a major conformational change arising from the interaction of AuNPs with zein. Also, we recorded FT-IR spectrum of zein-AuNP thin film showing a broad peak at $1644 \mathrm{~cm}^{-1},{ }^{23}$ an additive spectrum of amide $\mathrm{C}=\mathrm{O}$ stretching of zein peptide chain and the AuNP (a)

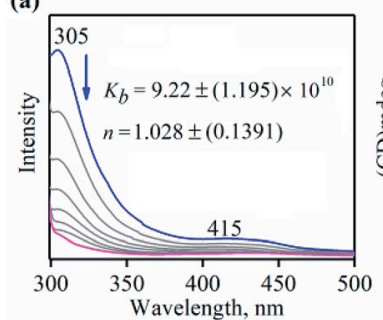

(c)

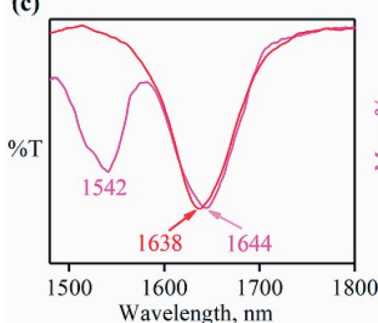

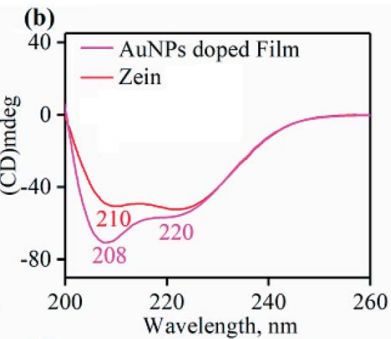

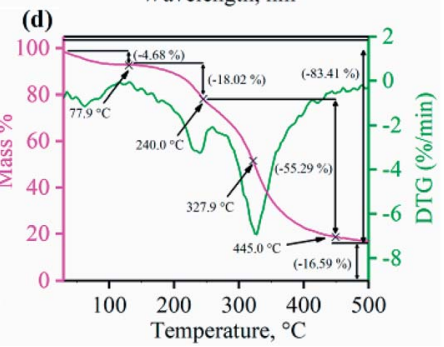

Fig. 2 (a) Fluorescence spectral changes of zein protein $(0.25 \mu \mathrm{M}$; blue line) upon addition of AuNPs (0.14 nM, red line) in $10 \mathrm{mM}$ SDS aqueous solution at $70{ }^{\circ} \mathrm{C}$. (b) CD spectra of AuNP doped zein film (magenta line) and zein (red line) recorded in aqueous medium at $25{ }^{\circ} \mathrm{C}$ (c) FT-IR spectra of film (magenta line) and AuNPs (red line) recorded in $\mathrm{KBr}$ at $25^{\circ} \mathrm{C}$. (d) TGA graph of the AuNP doped film recorded from room temperature to $500^{\circ} \mathrm{C}$. caped zein ligand $\left[\left(1650 \mathrm{~cm}^{-1}+1638 \mathrm{~cm}^{-1}\right) / 2=1644 \mathrm{~cm}^{-1}\right]$, clearly indicating a very strong binding between zein and AuNP caped zein ligand (Fig. 2c; ESI, Fig. S9†). This strong interaction contributes to the mechanical strength of the zein-AuNP thin film, which was further confirmed by the estimation of the tensile strength (TS) and strain at failure (E) (ESI, $\dagger$ ES, and Fig. $4 \mathrm{a}$ and b). ${ }^{47,48}$

The morphology of films in the presence and absence of AuNPs were probed with the help of Optical Microscope, Atomic Force Microscopy (AFM) and Scanning Electron Microscopy (SEM). Optical microscope and AFM images confirmed the change in the morphology of these films (Fig. 3a and ESI, Fig. S10 $\dagger$ ). The RMS roughness $(S q)$, amplitude $(A)$, and wavelength $(\lambda)$ of the buckled zein film were determined by the optical microscope and found to be $120.5 \mathrm{~nm}, 42 \mu \mathrm{m}, 137 \mu \mathrm{m}$ (Fig. 3b), respectively. Optical microscope and AFM images of the AuNP doped film showed that there is almost no buckling $(S q=1.6 \mathrm{~nm}$, Fig. 4c). However, the AFM resolution was not enough to observe small size AuNPs (Fig. 3a); yet the clear difference in surface morphology was observed for films with or without AuNPs (Fig. 4c, ESI, and Fig. S11 $\dagger$ ). The internal compressive stress causes buckling formation due to the difference in Young's modulus at the adjacent region. ${ }^{49,50}$ Doping of AuNPs enhances the effective modulus and decreases critical stress, which regulates the disparities in the tensile stress hence eliminate buckling. ${ }^{51}$ Surface topography of the film is a key factor in controlling the extent and alignment of the buckling. Alteration of surface topography as shown in the AFM image induced by NPs diminishes the buckling which in turn increase the mechanical strength as well as the smoothness of
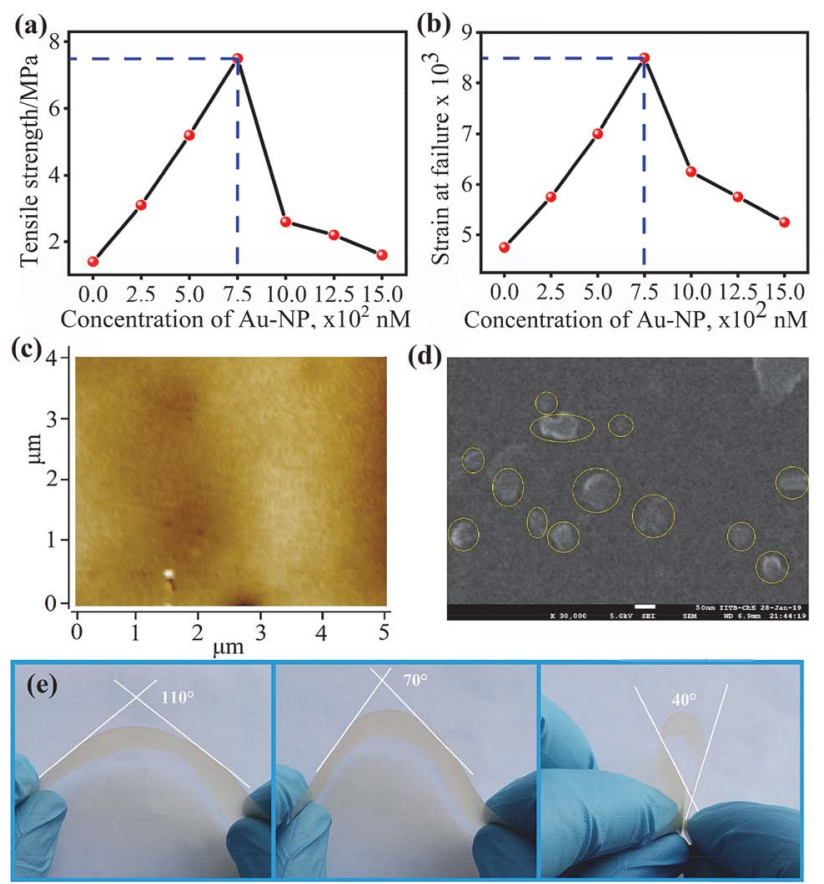

Fig. 3 (a) Optical microscope image of buckled zein protein film. The average wavelength was found to be $150 \mu \mathrm{m}$ (b) Optical microscope image of AuNPs doped zein protein film. The addition of AuNPs alleviates the compressive stress and prevents buckling. 

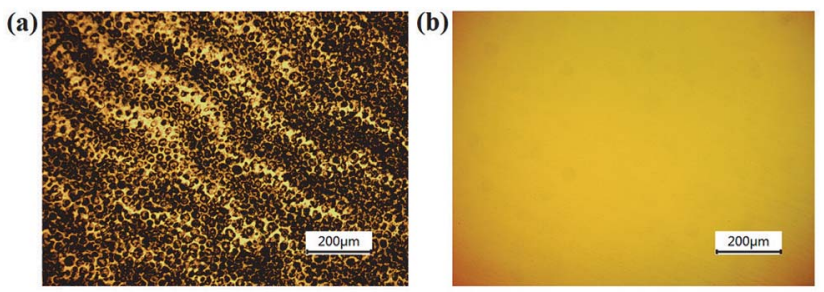

Fig. 4 (a) Tensile strength and (b) strain at failure of various films made from different amounts of AuNPs vs. zein (15\% v/v) (c) AFM image of zein protein film doped with AuNPs. (d) SEM image of AuNPs doped zein film showing the random distribution of NPs (yellow circles) (e) images of the AuNP functionalized film showing the bending at different angles.

the film surface (Fig. 4c). ${ }^{51}$ Additionally, SEM imaging was used to determine the surface as well as the distribution of AuNPs in the protein film. AuNPs embedded in the zein film appeared to be bigger than their independent size determined by TEM (Fig. 4d). This result also correlates with the shifting as well as the broadening of the SPR band in UV-visible spectra of the film from 550 to $560 \mathrm{~nm}$ (ESI, Fig. S11†).

These results are in good agreement with our observation (vide supra) of higher tensile strength for the films incorporated with AuNPs. Also, we have determined the thermal stability of AuNPs functionalized zein thin film from the TG-DSC experiment by following the temperature range from $27^{\circ} \mathrm{C}$ to $500{ }^{\circ} \mathrm{C}$. TG-DSC studies showed that the film could be easily used over a wide range of temperature $\left(0\right.$ to $\left.200{ }^{\circ} \mathrm{C}\right)$. However, the protein starts decomposing and completely burns out close to $328{ }^{\circ} \mathrm{C}$ (Fig. 2d). The thin film prepared from zein plus AuNPs showed the essential physical parameters such as flexibility, tensile strength, and strain required for a wide range of applications. The AuNPs functionalized film showed great flexibility, the bending at different angles suggesting high pliability, which is essential to adopt various from without breaking (Fig. 4e). Also, we have calculated the parameters (TS and $E$ ) by varying the ratio of AuNPs to zein. The titration of AuNPs with zein indicates the most suitable ratio for zein and AuNPs is $15 \% \mathrm{v} / \mathrm{v}$ to 7.5 $\times 10^{-2} \mathrm{nM}\left(\mathrm{TS}=7.5 \mathrm{MPa}, S=8.5 \times 10^{-3}\right)$, respectively. However, an increase in the amount of AuNPs to zein significantly decreases both TS and $E$, suggesting that an optimum amount of AuNPs required to improve the mechanical properties of zein films (ESI, Fig. S10†). Additionally, Young's modulus and hardness of AuNPs doped zein films were obtained by fitting the Derjaguin-Müller-Toporov (DMT) model to the section of the force-distance curve where zein and the tip are in contact, and by measuring the adhesion forces between the tip and the zein film. ${ }^{52,53}$ Force-distance curves were obtained and was compared with standard (polystyrene). Young's Modulus was found to be $3.6 \mathrm{MPa}$ (ESI ES and Fig. S12 $\dagger$ ).

In summary, we have demonstrated the synthesis of a novel zein thin film functionalized with AuNPs with increased mechanical properties. The characterization of AuNPs, as well as their interaction with zein protein, were studied using a combination of spectroscopic and microscopic techniques. We have also confirmed by FT-IR spectral data, for the first time, that the zein protein strongly binds on AuNPs' surface and also establishes that the free zein protein has a strong affinity towards the AuNPs. Also, physical parameters (tensile strength, strain, and Young's modulus) supports that the AuNPs' interactions provide the strength to zein film, which is further explained by the prevention of zein film buckling by the AuNPs interaction with zein protein. We believe that this is because of the decrease in compressive stress due to the uniform distribution of the AuNPs. We envisage that the further development of such proteins films with cheap, readily available metal oxides NPs will allow us to develop the materials for various industrial applications to a large extent.

\section{Conflicts of interest}

There are no conflicts of interest to declare.

\section{Acknowledgements}

This work was supported by Grants-in-Aid (Grant No. EEQ/2016/ 000466) from the Science and Engineering Research BoardDepartment of Science and Technology (SERB-DST). We thank Dr Jatish Kumar for the interpretation of AFM images.

\section{Notes and references}

1 J. R. Jambeck, R. Geyer, C. Wilcox, T. R. Siegler, M. Perryman, A. Andrady, R. Narayan and K. L. Law, Science, 2015, 347, 768-771.

2 C. M. Free, O. P. Jensen, S. A. Mason, M. Eriksen, N. J. Williamson and B. Boldgiv, Mar. Pollut. Bull., 2014, 85, 156-163.

3 K. Kaiser, M. Schmid and M. Schlummer, Recycling, 2017, 3, $1-26$.

4 R. Geyer, J. R. Jambeck and K. L. Law, Sci. Adv., 2017, 3, e1700782.

5 C. G. Avio, S. Gorbi and F. Regoli, Mar. Environ. Res., 2017, 128, 2-11.

6 Y. Y. Zhong, Y. B. Li, W. X. Liang, L. S. Liu, S. L. Li, J. Q. Xue and D. W. Guo, J. Food Process Eng., 2018, 41, e12645.

7 D. Klemm, B. Heublein, H. P. Fink and A. Bohn, Angew. Chem., Int. Ed., 2005, 44, 3358-3393.

8 Natural fibers, biopolymers, and biocomposites, ed. A. K. Mohanty, M. Misra and L. T. Drzal, Taylor \& Francis, 2005.

9 D. Garlotta, J. Polym. Environ., 2001, 9, 63-84.

10 B. P. Mooney, Biochem. J., 2009, 418, 219-232.

11 F. A. Momany, D. J. Sessa, J. W. Lawton, G. W. Selling, S. A. Hamaker and J. L. Willett, J. Agric. Food Chem., 2006, 54, 543-547.

12 P. Argos, K. Pedersen, M. D. Marks and B. A. Larkins, J. Biol. Chem., 1982, 257, 9984-9990.

13 T. P. Aydt, C. L. Weller and R. R. Testinlton, Trans. ASAE, 1991, 34, 207-211.

14 F. X. Budi Santosa and G. W. Padua, J. Agric. Food Chem., 1999, 47, 2070-2074.

15 H.-M. Lai and G. W. Padua, Cereal Chem., 1997, 74, 771-775. 16 J. W. Lawton, Cereal Chem., 2004, 81, 1-5. 
17 N. Parris and D. R. Coffin, J. Agric. Food Chem., 1997, 45, 1596-1599.

18 H.-M. Lai, G. W. Padua and L. S. Wei, Cereal Chem., 1997, 74, 83-90.

19 H. J. Park, J. M. Bunn, C. L. Weller, P. J. Vergano and R. F. Testin, Trans. ASAE, 1994, 37, 1281-1285.

20 N. Vahedikia, F. Garavand, B. Tajeddin, I. Cacciotti, S. M. Jafari, T. Omidi and Z. Zahedi, Colloids Surf., B, 2019, 177, 25-32.

21 J. O. Morales, A. C. Ross and J. T. McConville, J. Pharm. Pharmacol., 2013, 65, 827-838.

22 V. L. Colvin and K. M. Kulinowski, Proc. Natl. Acad. Sci. U. S. A., 2007, 104, 8679-8680.

23 G. Labib, Expert Opin. Drug Delivery, 2018, 15, 65-75.

24 K. G. DeFrates, R. Moore, J. Borgesi, G. Lin, T. Mulderig, V. Beachley and X. Hu, Nanomaterials, 2018, 8, 457-483.

25 D. Qin, L. Zhang, X. Du, Y. Wang and Q. Zhang, J. Nanopart. Res., 2016, 18, 254.

26 A. Mahal, P. Khullar, H. Kumar, G. Kaur, N. Singh, M. Jelokhani-Niaraki and M. S. Bakshi, ACS Sustainable Chem. Eng., 2013, 1, 627-639.

27 K. K. Li, S. W. Yin, X. Q. Yang, C. H. Tang and Z. H. Wei, J. Agric. Food Chem., 2012, 60, 11592-11600.

28 V. I. Dodero, Z. B. Quirolo and M. A. Sequeira, Front. Biosci., Landmark Ed., 2011, 16, 61-73.

29 I. B. Grishina and R. W. Woody, Faraday Discuss., 1994, 99, 245-262.

30 S. W. Provencher and J. Glockner, Biochemistry, 1981, 20, $33-$ 37.

31 D. Zhang, O. Neumann, H. Wang, V. M. Yuwono, A. Barhoumi, M. Perham, J. D. Hartgerink, P. WittungStafshede and N. J. Halas, Nano Lett., 2009, 9, 666-671.

32 N. Biswas, A. J. Waring, F. J. Walther and R. A. Dluhy, Biochim. Biophys. Acta, 2007, 1768, 1070-1082.

33 K. Moriyama, K. Hirao and K. Takeda, Colloid Polym. Sci., 2000, 278, 979-985.

34 Z. J. Deng, M. Liang, M. Monteiro, I. Toth and R. F. Minchin, Nat. Nanotechnol., 2011, 6, 39-44.

35 R. G. Aswathy, S. Balasubramanian, B. Dhandayudhapani, F. Takahiro, Y. Yasuhiko, M. Toru and D. S. Kumar, Adv. Nat. Sci.: Nanosci. Nanotechnol., 2012, 3, 025006.
36 A. A. Kamnev, Infrared spectroscopy in studying biofunctionalised gold nanoparticles, in Nanomaterials Imaging Techniques, Surface Studies, and Applications, Springer, 2013, pp. 35-50.

37 M. Hanauer, S. Pierrat, I. Zins, A. Lotz and C. Sonnichsen, Nano Lett., 2007, 7, 2881-2885.

38 Principles of Fluorescence Spectroscopy, ed. J. R. Lakowicz, 2006.

39 R. Shukla and M. Cheryan, Ind. Crops Prod., 2001, 13, 171192.

40 S. P. Boulos, T. A. Davis, J. A. Yang, S. E. Lohse, A. M. Alkilany, L. A. Holland and C. J. Murphy, Langmuir, 2013, 29, 14984-14996.

41 C. Wang, Q. H. Wu, C. R. Li, Z. Wang, J. J. Ma, X. H. Zang and N. X. Qin, Anal. Sci., 2007, 23, 429-433.

42 J. N. Weiss, FASEB J., 1997, 11, 835-841.

43 P. Satzer, F. Svec, G. Sekot and A. Jungbauer, Eng. Life Sci., 2016, 16, 238-246.

44 T. C. Bicudo, R. C. Bicudo, L. A. Forato, L. M. Beltramini, L. A. R. Batista, R. B. Filho and L. A. Colnago, Biopolymers, 2008, 89, 175-178.

45 S. Venyaminov and K. S. Vassilenko, Anal. Biochem., 1994, 222, 176-184.

46 P. Manavalan and W. C. Johnson Jr, Nature, 1983, 305, 831832.

47 R. Kumar, Ind. Eng. Chem. Res., 2010, 49, 3479-3484.

48 Q. Wang and G. W. Padua, J. Agric. Food Chem., 2005, 53, 3444-3448.

49 P. J. Yoo, K. Y. Suh, S. Y. Park and H. H. Lee, Adv. Mater., 2002, 14, 1383-1387.

50 G. M. Whitesides, N. Bowden, S. Brittain, A. G. Evans and J. W. Hutchinson, Nature, 1998, 393, 146-149.

51 T. R. Hendricks and I. Lee, Nano Lett., 2007, 7, 372-379.

52 M. Lorenzoni, L. Evangelio, S. Verhaeghe, C. Nicolet, C. Navarro and F. Pérez-Murano, Langmuir, 2015, 31, 11630-11638.

53 O. Krivosheeva, M. Sababi, A. Dedinaite and P. M. Claesson, Langmuir, 2013, 29, 9551-9561. 